\title{
Head-to-head comparison of qSOFA and SIRS criteria in predicting the mortality of infected patients in the emergency department: a meta-analysis
}

Jianjun Jiang, Jin Yang, Jing Mei, Yongmei Jin and Youjin Lu*

\begin{abstract}
Background: Recently, the concept of sepsis was redefined by an international task force. This international task force of experts recommended using the quick Sequential Organ Failure Assessment (qSOFA) criteria instead of the systemic inflammatory response syndrome (SIRS) criteria to classify patients at high risk for death. However, the added value of these new criteria in the emergency department (ED) remains unclear. Thus, we performed this meta-analysis to determine the diagnostic accuracy of the GSOFA criteria in predicting mortality in ED patients with infections and compared the performance with that of the SIRS criteria.

Methods: PubMed, EMBASE and Google Scholar (up to April 2018) were searched for related articles. A $2 \times 2$ contingency table was constructed according to mortality and qSOFA score $(<2$ and $\geq 2)$ or SIRS score $(<2$ and $\geq$ 2) in ED patients with infections. Two investigators independently assessed study eligibility and extracted data. We used a bivariate meta-analysis model to determine the prognostic value of qSOFA and SIRS in predicting mortality. We used the $\mathrm{I}^{2}$ index to test heterogeneity. The bivariate random-effects regression model was used to pool the individual sensitivity, specificity, diagnostic odds ratio (DOR), positive likelihood ratio (PLR), and negative likelihood ratio (NLR). The summary receiver operating characteristic curve (SROC) was constructed to assess the overall diagnostic accuracy.
\end{abstract}

Results: Eight studies with a total of 52,849 patients were included. A qSOFA score $\geq 2$ was associated with a higher risk of mortality in ED patients with infections, with a pooled risk ratio (RR) of 4.55 ( $95 \% \mathrm{Cl}, 3.38-6.14)$ using a random-effects model $\left(I^{2}=91.1 \%\right)$. A SIRS score $\geq 2$ was a prognostic marker of mortality in ED patients with infections, with a pooled RR of $2.75(95 \% \mathrm{Cl}, 1.96-3.86)$ using a random-effects model $\left(\mathrm{I}^{2}=89 \%\right)$. When comparing the performance of qSOFA and SIRS in predicting mortality, a qSOFA score $\geq 2$ was more specific; however a SIRS score $\geq 2$ was more sensitive. The initial qSOFA values were of limited prognostic value in ED patients with infections.

Conclusions: A qSOFA score $\geq 2$ and SIRS score $\geq 2$ are strongly associated with mortality in ED patients with infections. However, it is also clear that QSOFA and SIRS have limitations as risk stratification tools for ED patients with infections.

Keywords: SIRS, qSOFA, Infection, Emergency department, Mortality, Prognosis

\footnotetext{
* Correspondence: luyougolden@hotmail.com

Department of Respiratory Medicine, the Second Affiliated Hospital of Anhui
}

Medical University, Hefei, China

(c) The Author(s). 2018 Open Access This article is distributed under the terms of the Creative Commons Attribution 4.0 International License (http://creativecommons.org/licenses/by/4.0/), which permits unrestricted use, distribution, and reproduction in any medium, provided you give appropriate credit to the original author(s) and the source, provide a link to the Creative Commons license, and indicate if changes were made. The Creative Commons Public Domain Dedication waiver (http://creativecommons.org/publicdomain/zero/1.0/) applies to the data made available in this article, unless otherwise stated. 


\section{Background}

Sepsis is a common cause of critical illness and mortality worldwide [1, 2], accounting for $10 \%$ of intensive care unit (ICU) cases, and it has an in-hospital mortality rate of 10 to $20 \%$ [3-5]. However, both the risk stratification in patients with acute infections and the identification of sepsis are still challenges for clinicians. Therefore, a reliable method for evaluating the severity of sepsis may help clinicians determine whether aggressive therapy and close monitoring are more appropriate than conservative therapy, thus improving patients' initial management and, ultimately, survival.

The previous consensus definitions of sepsis required an infection and two or more systemic inflammatory response syndrome (SIRS) criteria [6,7]. Four SIRS criteria were defined, namely, tachypnea (respiratory rate $>20$ breaths per minute), tachycardia (heart rate $>$ 90 beats per minute), leukopenia or leukocytosis (leucocyte count $>12,000$ cells $/ \mu \mathrm{L}$ or $<4000 / \mu \mathrm{L}$ ), and fever or hypothermia (body temperature $>38{ }^{\circ} \mathrm{C}$ or $<36{ }^{\circ} \mathrm{C}$, respectively). Recently, this syndrome was redefined by an international task force in the third international consensus definitions for sepsis and septic shock (sepsis-3) [8]. Furthermore, the new definition has discarded the concept of SIRS. A new set of criteria, included in the quick Sequential Organ Failure Assessment (qSOFA), was introduced in sepsis-3 (range, 0-3; each receiving 1 point if the following criteria are met: systolic arterial blood pressure $\leq$ $100 \mathrm{mmHg}$; respiratory rate $>21$ breaths $/ \mathrm{min}$; or altered mental status). A qSOFA score of 2 or higher was associated with a higher risk of mortality. The definition group stated that qSOFA was a better predictor of mortality than SIRS and recommended using a qSOFA score of $\geq 2$, instead of a SIRS score of $\geq 2$, to identify infected patients at high risk for death. However, the added value of these new criteria in specific clinical settings remains unclear, including in the emergency department (ED).

We included all studies that compared qSOFA and SIRS scores in ED patients with infections and performed a meta-analysis of the available studies to determine the diagnostic accuracy of the qSOFA criteria in predicting mortality in ED patients with infections. The performance of the qSOFA criteria was compared with that of the SIRS criteria.

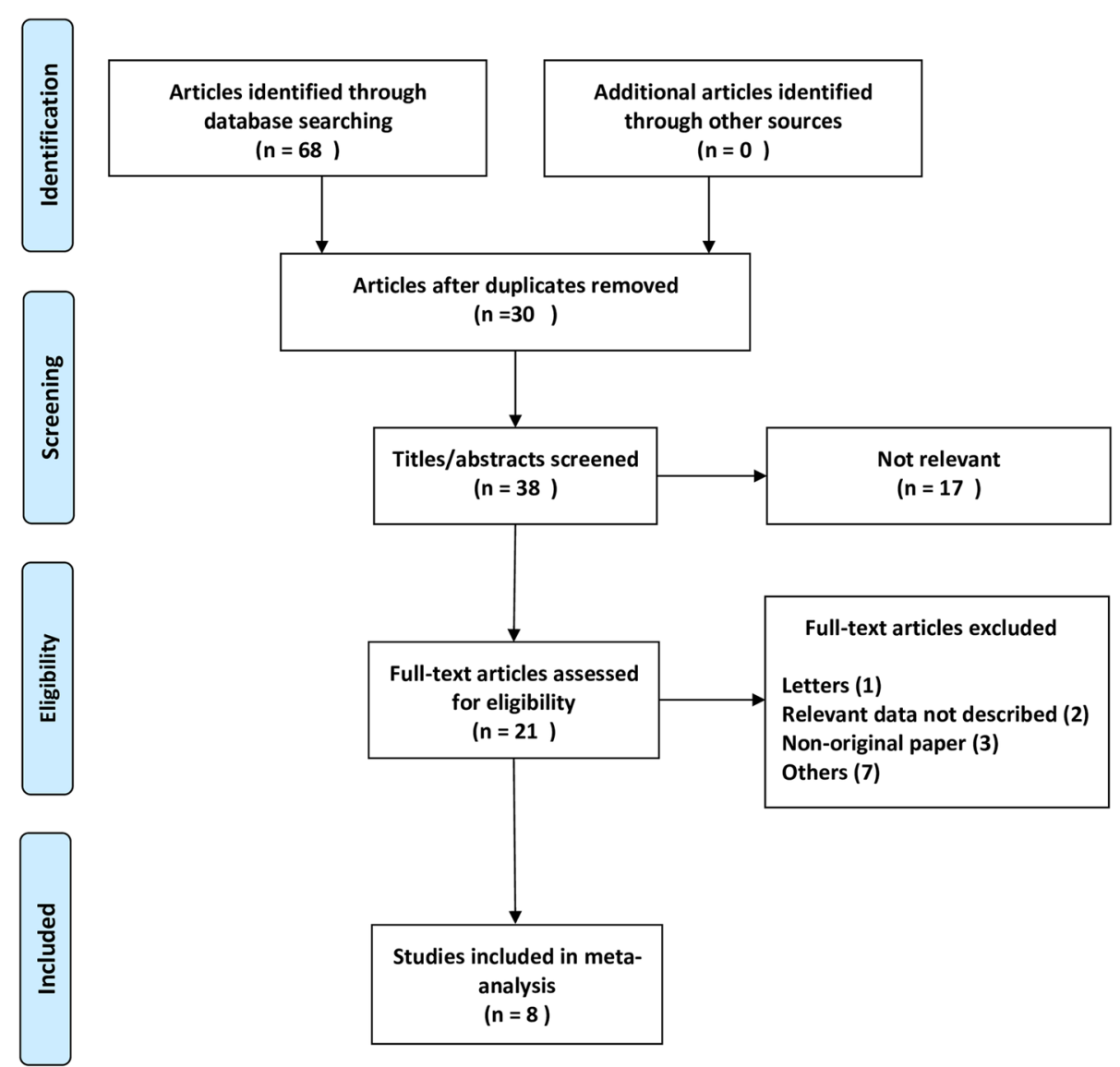

Fig. 1 Flow diagram of the study selection process 
Table 1 Study characteristics

\begin{tabular}{|c|c|c|c|c|c|c|c|c|c|}
\hline Author/year & Study design & Country & $\begin{array}{l}\text { Sample } \\
\text { size (n) }\end{array}$ & $\begin{array}{l}\text { Age } \\
\text { (mean) }\end{array}$ & $\begin{array}{l}\text { Male } \\
(\%)\end{array}$ & $\begin{array}{l}\text { Prevalence of } \\
\text { mortality (\%) }\end{array}$ & $\begin{array}{l}\text { Time of score } \\
\text { calculation }\end{array}$ & $\begin{array}{l}\text { Measured } \\
\text { mortality }\end{array}$ & Participant selection \\
\hline Goulden/2018 & Retrospective & UK & 1818 & 68 & 51 & 14.6 & ED arrival & $\begin{array}{l}\text { In-hospital } \\
\text { mortality }\end{array}$ & Suspected infection \\
\hline Ranzani/2017 & Retrospective & Spain & 6874 & 66 & 62 & 6.4 & ED arrival & $\begin{array}{l}\text { In-hospital } \\
\text { mortality }\end{array}$ & $\begin{array}{l}\text { Community-acquired } \\
\text { pneumonia }\end{array}$ \\
\hline $\begin{array}{l}\text { González Del } \\
\text { Castillo/2017 }\end{array}$ & Prospective & Spain & 1071 & 84 & 51 & 6.5 & ED arrival & $\begin{array}{l}\text { 30-day } \\
\text { mortality }\end{array}$ & $\begin{array}{l}\text { Suspected or } \\
\text { confirmed infection }\end{array}$ \\
\hline Askim/2017 & Prospective & Norway & 1535 & 62 & 53 & 4.4 & ED arrival & $\begin{array}{l}\text { 30-day } \\
\text { mortality }\end{array}$ & Suspected infection \\
\hline Moskowitz/2017 & Retrospective & USA & 24,164 & 64 & 51 & 4.9 & ED arrival & $\begin{array}{l}\text { In-hospital } \\
\text { mortality }\end{array}$ & Suspected infection \\
\hline Willams/2017 & Retrospective & Australia & 8871 & 49 & 51 & 8.7 & $\begin{array}{l}\text { Worst values } \\
\text { during ED stay }\end{array}$ & $\begin{array}{l}\text { 30-day } \\
\text { mortality }\end{array}$ & Suspected infection \\
\hline Freund/2017 & Prospective & Europe & 879 & 67 & 53 & 8.4 & $\begin{array}{l}\text { Worst values } \\
\text { during ED stay }\end{array}$ & $\begin{array}{l}\text { In-hospital } \\
\text { mortality }\end{array}$ & Suspected infection \\
\hline Henning $[a] / 2017$ & Prospective & USA & 4618 & 57 & 52 & 4.2 & $\begin{array}{l}\text { Worst values } \\
\text { during ED stay }\end{array}$ & $\begin{array}{l}\text { In-hospital } \\
\text { mortality }\end{array}$ & Suspected infection \\
\hline $\begin{array}{l}\text { Henning [b]/ } \\
2017\end{array}$ & Prospective & USA & 2132 & 57 & 52 & 3.9 & $\begin{array}{l}\text { Worst values } \\
\text { during ED stay }\end{array}$ & $\begin{array}{l}\text { In-hospital } \\
\text { mortality }\end{array}$ & Suspected infection \\
\hline
\end{tabular}

\section{Methods}

This meta-analysis was performed in accordance with the Preferred Reporting Items for Systematic Reviews and Meta-Analyses (PRISMA) statement.

\section{Search strategy and selection criteria}

We systematically searched the literature using PubMed, EMBASE and Google Scholar before April 2018. The search strategy was as follows: ("quick Sequential Organ Failure Assessment" or "qSOFA") and ("Systemic Inflammatory Response Syndrome" or "SIRS") and ("infection" or "infections") and ("Emergency Department" or "ED"). The search was restricted to studies written in English. To ensure a comprehensive literature search, we also examined the references of the included articles.

Two investigators (Jianjun Jiang and Jin Yang) independently screened and included eligible studies, and any disagreement was resolved by group consensus. The inclusion criteria were the following: (1) the study population included ED patients with infections, (2) a clear diagnostic reference standard for infection was used, (3) the purpose was to evaluate or compare the prognostic value of qSOFA and SIRS in predicting death within the same patient population, and (4) adequate information had to be provided to build a $2 \times 2$ contingency table (true positives [TP], false positives [FP], false negatives $[\mathrm{FN}]$, and true negatives [TN]). The exclusion criteria were as follows: review articles, letters, conference abstracts, and expert opinions.

\section{Data extraction and quality assessment}

The following data were extracted from the original studies: first author, year of publication, study design, country of origin, sample size, prevalence of mortality, endpoint, mean ages, ratio of male patients, time point of score calculation, TP, FP, FN, and TN. We contacted authors with any items that required clarification. To assess quality, modified criteria based on the criteria of

Table 2 Study quality assessment

\begin{tabular}{|c|c|c|c|c|c|c|c|}
\hline Study & Population & Follow-up & $\begin{array}{l}\text { Measurement of } \\
\text { severity scores }\end{array}$ & Outcome measurement & $\begin{array}{l}\text { confounding } \\
\text { variables }\end{array}$ & Statistical analysis & Quality score(total) \\
\hline Goulden/2018 & 2 & 1 & 2 & 2 & 2 & 1 & 10 \\
\hline Ranzani/2017 & 2 & 1 & 1 & 2 & 2 & 2 & 10 \\
\hline González DelCastillo/2017 & 2 & 2 & 2 & 2 & 1 & 2 & 11 \\
\hline Askim/2017 & 2 & 2 & 2 & 2 & 1 & 2 & 11 \\
\hline Moskowitz/2017 & 2 & 1 & 2 & 2 & 2 & 1 & 10 \\
\hline Willams/2017 & 2 & 1 & 1 & 2 & 2 & 1 & 9 \\
\hline Freund/2017 & 2 & 2 & 1 & 1 & 2 & 2 & 10 \\
\hline Henning/2017 & 2 & 1 & 1 & 2 & 2 & 1 & 9 \\
\hline
\end{tabular}




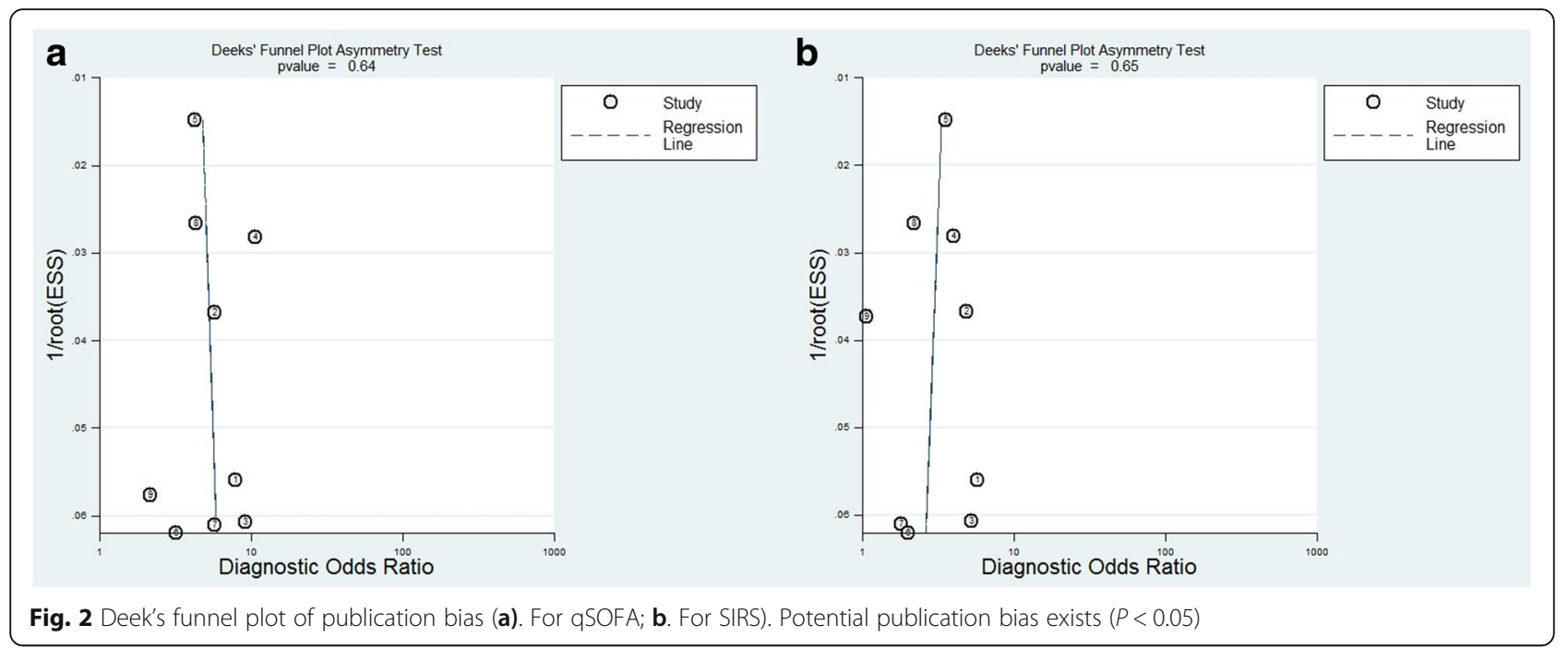

Hayden et al. were used [9](Additional File 1). We assessed the following six items: (1) population, (2) follow-up, (3) measurement of severity scores, (4) outcome measurement, (5) confounding variables, and (6) statistical analysis. Each item was scored from 0 to 2, and the total scores ranged from 0 to 12 . When publications had scores $\geq 9$, the methodological study design was considered acceptable.

\section{Statistical analysis}

Statistical analysis was conducted using the MIDAS module of the STATA software, version 12.0 (Stata

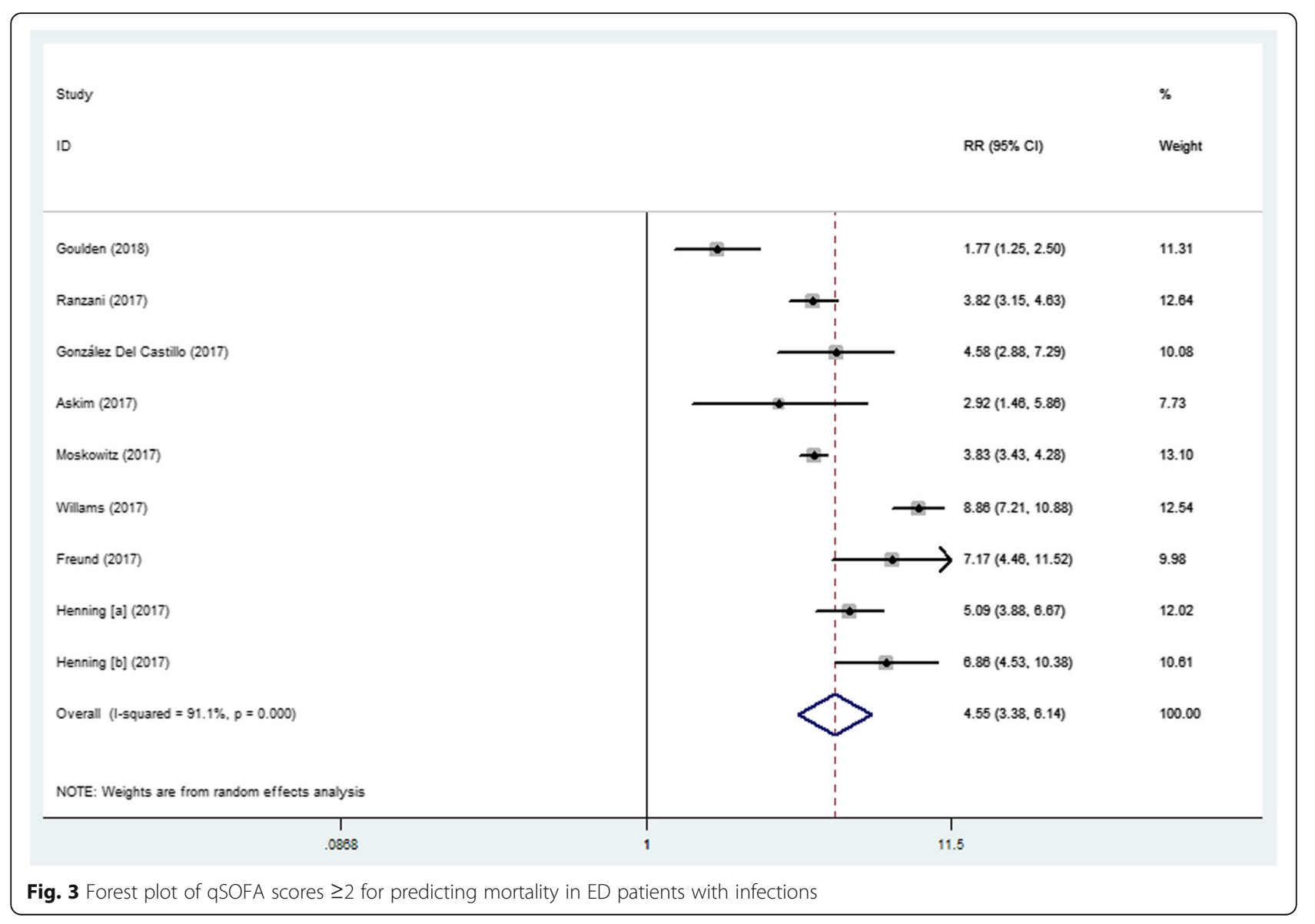




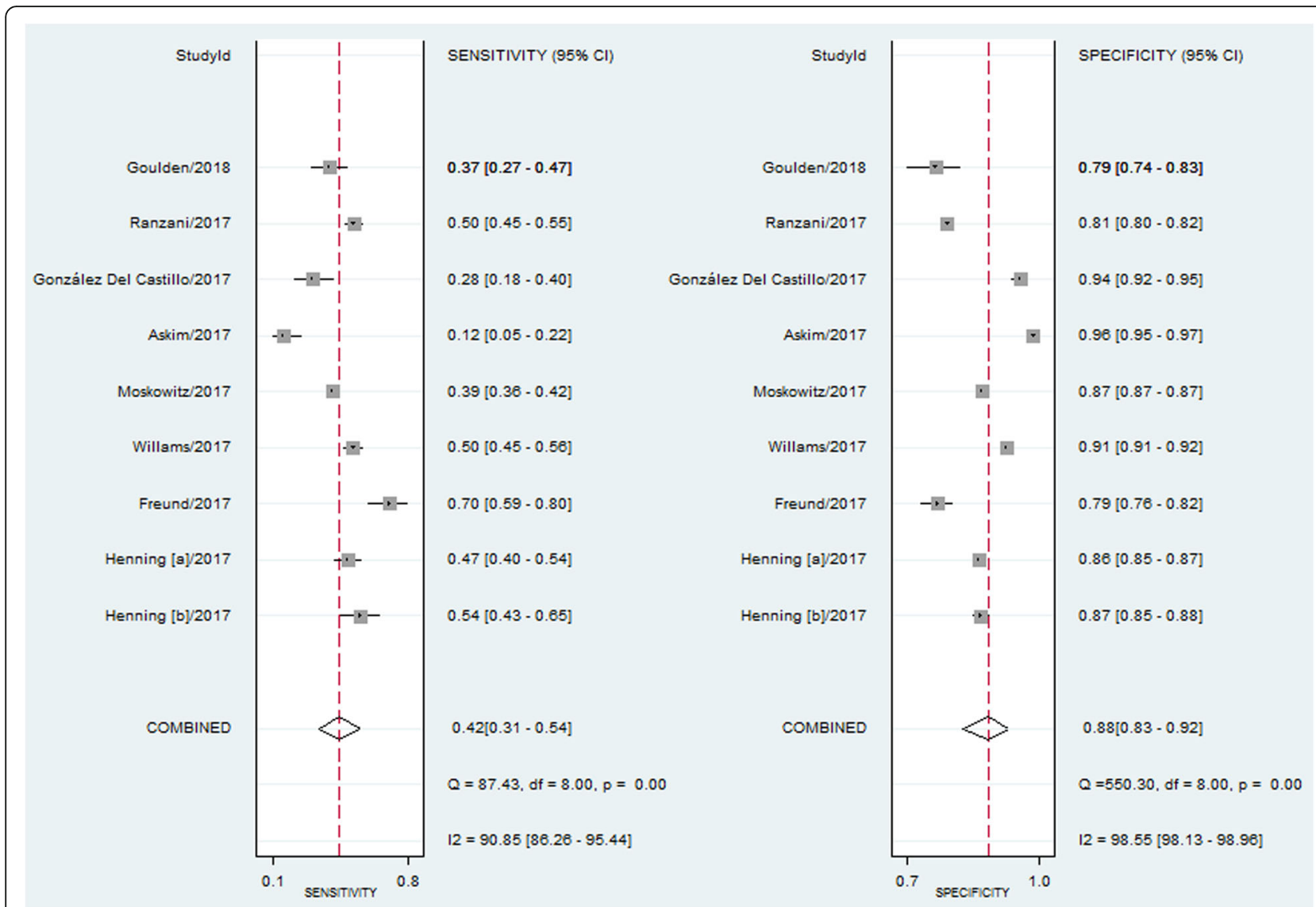

Fig. 4 Forest plot of the sensitivity and specificity of qSOFA scores $\geq 2$ for predicting mortality in ED patients with infections

Corporation, College Station, TX), Meta-Disc 1.4 (XI Cochrane Colloquium, Barcelona, Spain) and RevMan5.3 (Nordic Cochrane Center, Copenhagen, Denmark). We identified TP, FN, FP, and TN based on the effects of qSOFA (scores $<2$ and $\geq 2$ ) or SIRS (scores $<2$ and $\geq 2$ ) on all-cause mortality. Relative risk (RR) was used to evaluate the predictive value of qSOFA and SIRS, which was pooled by random-effects or fixed-effects models, according to DerSimonian and Laird's method [10]. $\mathrm{I}^{2}$ statistics were calculated to assess statistical heterogeneity; $\mathrm{I}^{2}$ values of more than $50 \%$ indicated a significant level of heterogeneity [10]. If $\mathrm{I}^{2}$ was $>50 \%$, the random-effects model was chosen; otherwise, the fixed-effects model was used.

The pooled sensitivity, specificity, diagnostic odds ratio (DOR), positive likelihood ratio (PLR) and negative likelihood ratio (NLR) were calculated using a bivariate random-effects regression model [11, 12]. A summary receiver operating characteristic curve (SROC) was generated to assess the overall diagnostic accuracy [13].

We conducted a subgroup analysis to explore the main source of heterogeneity and explore the prognostic accuracy of qSOFA and SIRS when studies were restricted to different follow-up periods (30-day mortality and in-hospital mortality), used different time points to calculate scores (using the earliest measured clinical values or the worst values to calculate qSOFA and SIRS scores), or were prospective or retrospective studies only. Publication bias was analysed by Deek's funnel plot.

\section{Results}

Our database search retrieved 68 articles. According to the exclusion and inclusion criteria, 8 studies [14-21] met our eligibility criteria and were included in the analysis (Fig. 1). In one study, the authors reported the diagnostic accuracy for two groups of patients separately; therefore, we divided the results of the study into two parts. Thus, we analysed 9 datasets. No additional relevant articles were identified in the bibliographies of the original articles.

\section{Study characteristics}

The main characteristics of the included studies are shown in Table 1. The eight included studies were published between 2017 and 2018. Five studies [14$17,20]$ were conducted in Europe, two $[18,21]$ were conducted in the United States, and one [19] was conducted in Australia. All the studies were carried 


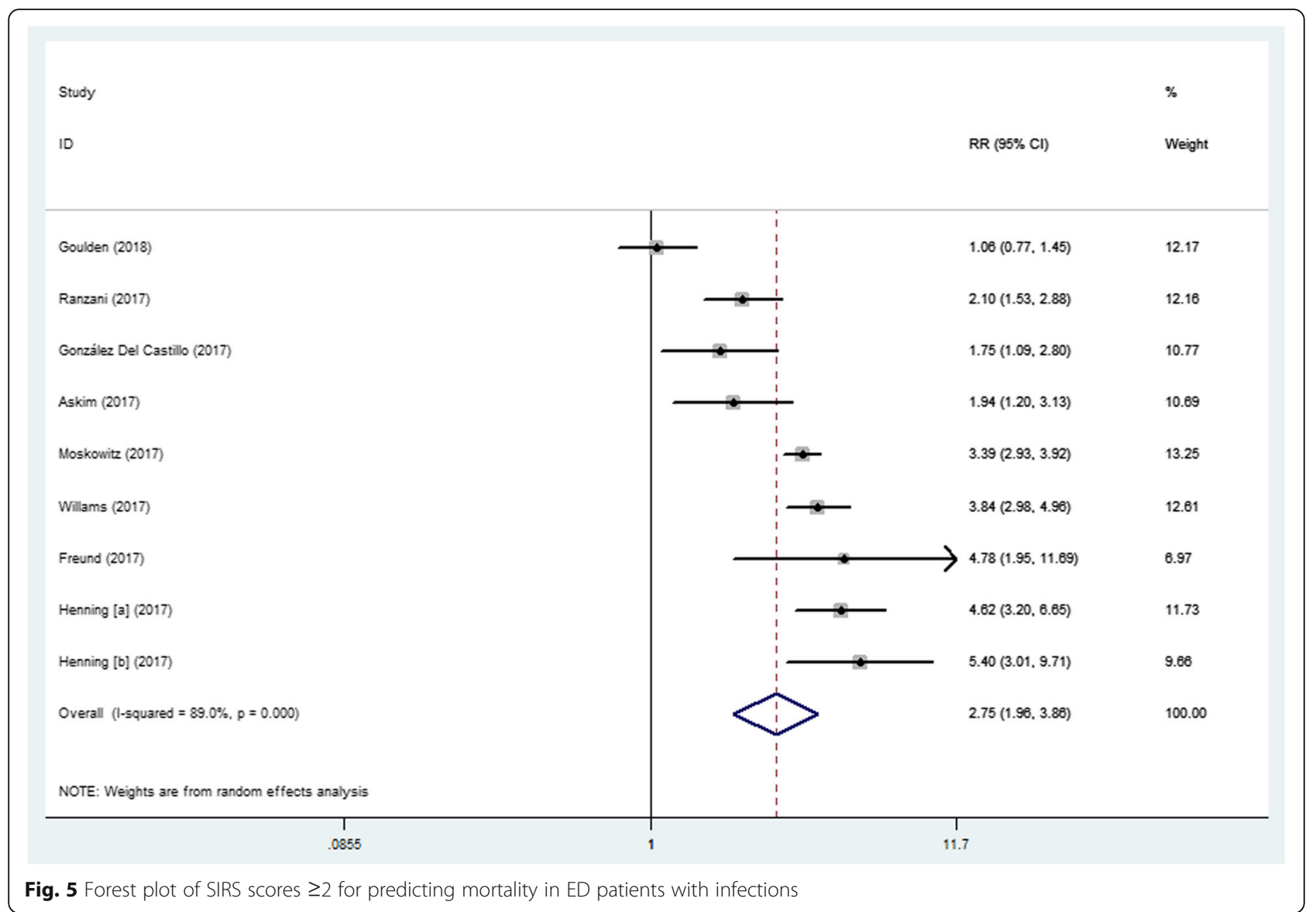

out in EDs and published in English. The proportion of men varied between 50 and $62 \%$, and the mortality rates varied from 4.4 to $14.6 \%$ in these studies. The most frequent site of infection was the respiratory system. The majority of the studies used in-hospital mortality or 30-day mortality as their primary outcome measure. Five cohorts $[16,17,20,21]$ were prospective, observational cohort studies, and four [14, $15,18,19]$ studies were described as retrospective. Among these datasets, five [14-18] used the first set of available laboratory values and vital signs to calculate the SIRS and qSOFA scores, and four [19-21] studies used the worst values during the ED stay to calculate the SIRS and qSOFA scores.

\section{Quality assessment and publication bias}

We conducted a quality assessment based on the criteria developed by Hayden et al. [9]. Six studies [14, 15, 1821 ] were considered to be of moderate quality (9 to 10), and two studies $[16,17]$ were of good quality $(\geq 11)$ (Table 2). Deek's Funnel plot indicated that no publication bias existed (Fig. 2).

\section{Data synthesis and meta-analysis}

Analysis of the association between qSOFA scores and mortality

All the included studies indicated that a qSOFA score of $\geq 2$ was associated with a higher risk of mortality in ED patients with infections, with a RR ranging from 1.77 to 8.86. Due to the significant heterogeneity between studies $\left(\mathrm{I}^{2}=91.1 \%\right)$, we used a random-effects model for pooled RR estimates. The pooled RR was 4.55 (95\% CI, 3.38-6.14) (Fig. 3). The pooled sensitivity and specificity were 0.42 (95\% CI, 0.31-0.54) and 0.88 (95\% CI, 0.830.92), respectively (Fig. 4). Furthermore, the pooled DOR, PLR, NLR, and AUC were 5 (95\% CI, 4-7), 3.5 (95\% CI, 2.80-4.40), 0.66 (95\% CI, 0.56-0.78), and 0.78 (95\% CI, 0.74-0.81), respectively.

\section{Analysis of the association between SIRS scores and mortality}

Combined data from all eight studies indicated that a SIRS score of $\geq 2$ was associated with a higher risk of mortality, with pooled RR estimates of 2.75 (95\% CI, 1.96-3.86) and substantial heterogeneity in the data $\left(\mathrm{I}^{2}=89 \%\right)$ (Fig. 5). The pooled sensitivity and specificity 


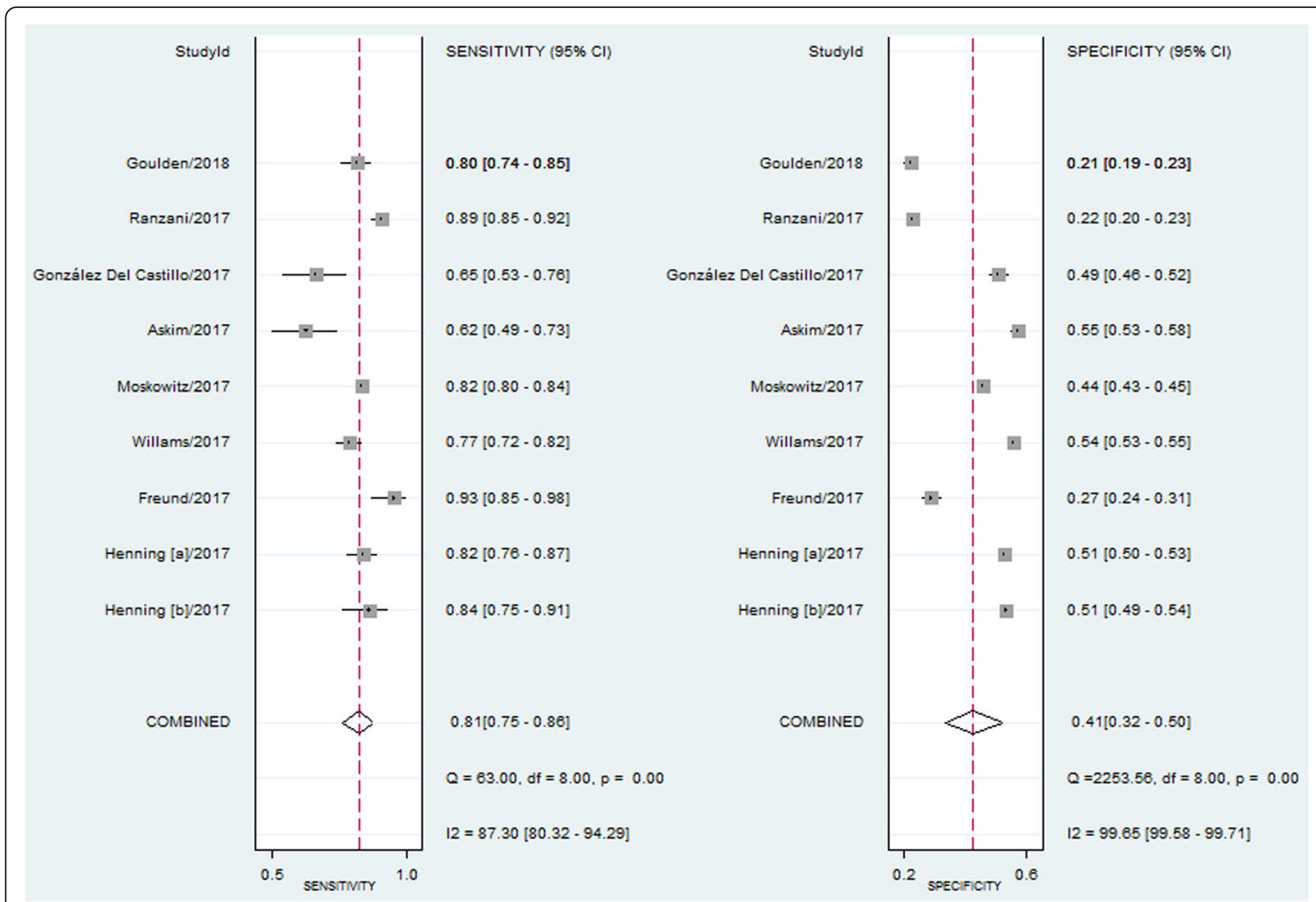

Fig. 6 Forest plot of the sensitivity and specificity of SIRS scores $\geq 2$ on predicting mortality in ED patients with infections

were 0.81 (95\% CI, 0.75-0.86) and 0.41 (95\% CI, 0.320.50), respectively (Fig. 6). Additionally, the pooled DOR, PLR, NLR, and AUC were 3 (95\% CI, 2-4), 1.40 (95\% CI, 1.20-1.60), 0.47 (95\% CI, 0.37-0.59), and 0.70 (95\% CI, $0.65-0.73)$, respectively.

\section{Performance comparison of qSOFA and SIRS}

The performance characteristics of qSOFA and SIRS are shown in Table 3. Direct comparisons of data in the studies are shown in Fig. 7. Regardless of whether the comparisons were direct or indirect, they all consistently indicated that a qSOFA score $\geq 2$ was more specific, but less sensitive, than a SIRS score $\geq 2$ in predicting mortality. As shown in Table 3, qSOFA had a superior positive likelihood ratio compared with that of SIRS, but SIRS had a relatively good negative likelihood ratio.

\section{Subgroup analysis}

A subgroup analysis restricted to different follow-up periods, studies using different time points to calculate scores, prospective studies and retrospective studies was performed (Table 4). Studies that used the first measured laboratory values and vital signs to calculate scores had a low sensitivity for qSOFA in predicting mortality in ED patients with infections. Due to the relatively low sensitivity, the initial qSOFA values were of limited prognostic value in ED patients with infections. In addition, studies that used the worst values to calculate qSOFA had a relatively good prognostic performance.

\section{Discussion}

As sepsis is a common cause of critical illness and mortality among infected patients, the early diagnosis and identification of sepsis is paramount to ensure early

Table 3 Pooled performance characteristics of qSOFA and SIRS criteria for predicting mortality in ED patients with infections

\begin{tabular}{lllllll}
\hline & Sensitivity $(95 \% \mathrm{Cl})$ & Specificity $(95 \% \mathrm{Cl})$ & PLR $(95 \% \mathrm{Cl})$ & NLR $(95 \% \mathrm{Cl})$ & DOR $(95 \% \mathrm{Cl})$ & AUC (95\% Cl) \\
\hline qSOFA & $0.42(0.31-0.54)$ & $0.88(0.83-0.92)$ & $3.5(2.8-4.4)$ & $0.66(0.56-0.78)$ & $5(4-7)$ & $0.78(0.74-0.81)$ \\
SIRS & $0.81(0.75-0.86)$ & $0.41(0.32-0.50)$ & $1.4(1.2-1.6)$ & $0.47(0.37-0.59)$ & $3(2-4)$ & $0.70(0.65-0.73)$ \\
\hline
\end{tabular}

qSOFA, quick Sequential Organ Failure Assessment, SIRS, systemic inflammatory response syndrome, PLR positive likelihood ratio, NLR negative likelihood ratio, $D O R$ diagnostic odds ratio, $A \cup C$ area under the curve, $\mathrm{Cl}$ confidence interval 


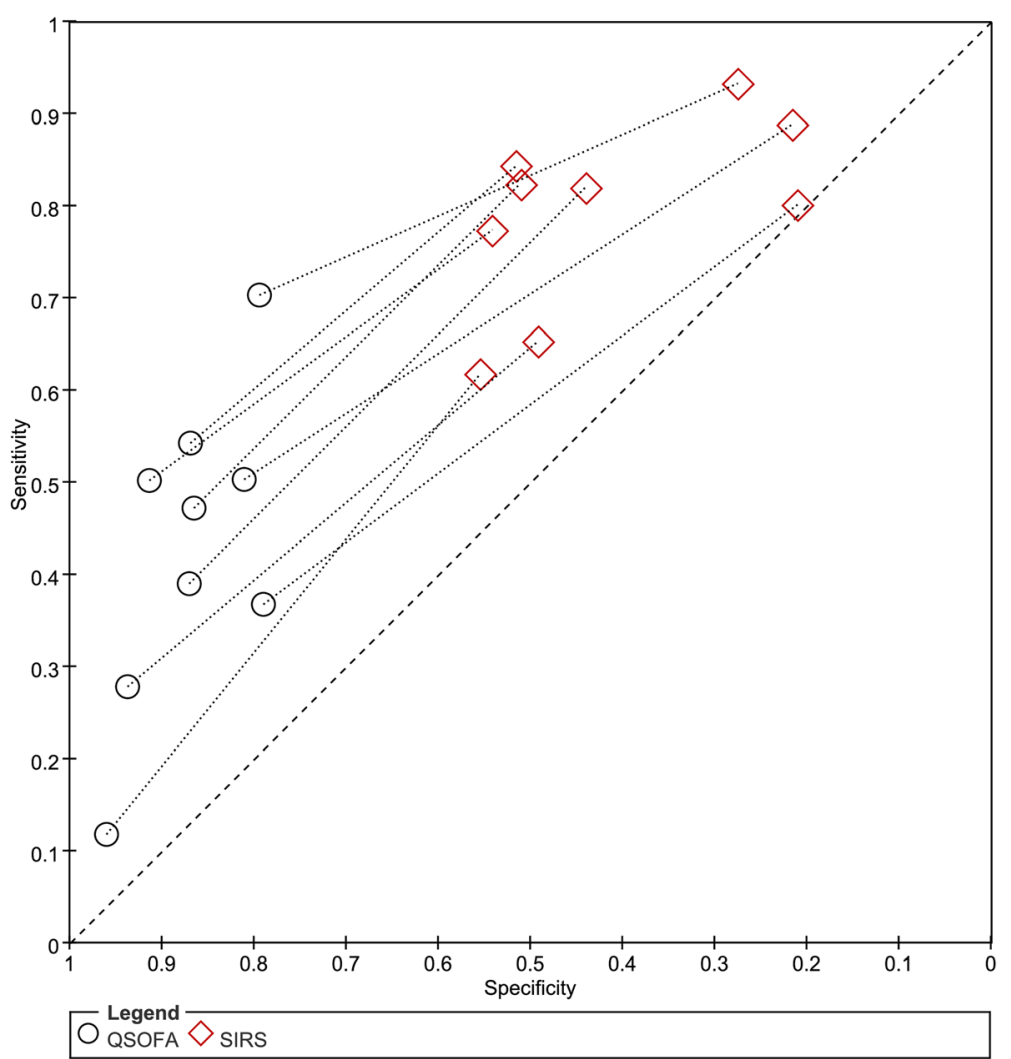

Fig. 7 Paired specificity and sensitivity of qSOFA scores $\geq 2$ versus SIRS scores $\geq 2$ in predicting mortality in ED patients with infections

antibiotic administration and resuscitative therapies. To our knowledge, this is the first meta-analysis and systematic review comparing the performance of the new sepsis definitions with the previous definitions in predicting mortality in ED patients with infections. We first determined that both a qSOFA score of $\geq 2$ and a SIRS score of $\geq 2$ were strongly associated with mortality in ED patients with infections. However, in terms of predicting mortality, qSOFA and SIRS have different trade-offs.

In this meta-analysis, we demonstrated that a qSOFA score of $\geq 2$ was associated with a higher risk of mortality in ED patients with infections. The pooled RR was 4.55 (95\% CI, 3.38-6.14), suggesting that a qSOFA score of $\geq 2$ predicted a moderate prognosis for ED patients with infections. We further evaluated the prognostic performance of qSOFA. The high specificity and good positive likelihood ratio of qSOFA are of great value for screening infected patients who are more likely to develop adverse outcomes. Therefore, the qSOFA criteria can be used to urge clinicians to further investigate the presence of organ dysfunction in infected patients, initiate or escalate appropriate therapy, and consider referring patients to the ICU. However, the poorer sensitivity of the qSOFA criteria means that even some patients who are actually at higher risk of death may be incorrectly classified and managed as non-severe. Perhaps the addition of biomarkers, such as lactate, is a possible solution [22, 23]. Notably, when the earliest measured clinical values were used to calculate the qSOFA score, the sensitivity of qSOFA in predicting mortality was quiet low. The initial qSOFA values were of limited prognostic value in ED patients with infections. With regard to the SIRS criteria, we found that a cut-off $\geq 2$ was a prognostic marker of mortality in ED patients with infections, with a pooled RR of 2.75 (95\% CI, 1.96-3.86). In terms of predicting mortality, we observed that the SIRS criteria could correctly identify patients who were at a low risk of death and had non-severe infections, with a pooled sensitivity of 0.81 (95\% CI, 0.75-0.86) and a pooled NLR of 0.47 (95\% CI, 0.37-0.59), thus giving clinicians more confidence in distinguishing patients who may not need to be hospitalized. However, we also observed that the SIRS criteria may lead to more FP, with a pooled specificity of 0.41 (95\% CI, $0.32-0.50)$, thus unnecessarily wasting time and resources.

When comparing the performance of qSOFA and SIRS, qSOFA had a relatively high AUC compared with that of SIRS; however, it should be stressed that the real characteristics of interest for clinical use are the 
Table 4 Subgroup analysis

\begin{tabular}{|c|c|c|c|c|c|c|}
\hline Subgroup & No. of studies & No. of patients & RR $(95 \% \mathrm{Cl})$ & SEN $(95 \% \mathrm{Cl})$ & SPE $(95 \% \mathrm{Cl})$ & Test for heterogeneity $\left(I^{2}\right)$ \\
\hline \multicolumn{7}{|l|}{ All studies } \\
\hline qSOFA & 8 & 52,849 & $4.55(3.38-6.14)$ & $0.42(0.31-0.54)$ & $0.88(0.83-0.92)$ & 91.1 \\
\hline SIRS & 8 & 52,849 & $2.75(1.96-3.86)$ & $0.81(0.75-0.86)$ & $0.41(0.32-0.50)$ & 89 \\
\hline \multicolumn{7}{|c|}{ Prospective studies } \\
\hline qSOFA & 4 & 11,122 & $5.34(4.19-6.82)$ & $0.39(0.22-0.60)$ & $0.90(0.83-0.94)$ & 37.2 \\
\hline SIRS & 4 & 11,122 & $3.23(1.95-4.33)$ & $0.80(0.67-0.89)$ & $0.47(0.38-0.56)$ & 78.5 \\
\hline \multicolumn{7}{|c|}{ Retrospective studies } \\
\hline qSOFA & 4 & 41,727 & $3.95(2.48-6.44)$ & $0.44(0.38-0.50)$ & $0.85(0.80-0.90)$ & 86.2 \\
\hline SIRS & 4 & 41,727 & $2.35(1.40-3.93)$ & $0.83(0.78-0.87)$ & $0.34(0.21-0.49)$ & 84.4 \\
\hline \multicolumn{7}{|c|}{ In-hospital mortality } \\
\hline qSOFA & 5 & 41,372 & $4.20(3.18-5.56)$ & $0.49(0.41-0.57)$ & $0.84(0.81-0.86)$ & 86.6 \\
\hline SIRS & 5 & 41,372 & $2.97(1.84-4.80)$ & $0.85(0.81-0.88)$ & $0.35(0.25-0.46)$ & 81.8 \\
\hline \multicolumn{7}{|c|}{ 30-day mortality } \\
\hline qSOFA & 3 & 11,477 & $5.22(2.70-10.07)$ & $0.41(0.37-0.46)$ & $0.92(0.92-0.93)$ & 84.1 \\
\hline SIRS & 3 & 11,477 & $2.42(1.40-4.23)$ & $0.74(0.69-0.78)$ & $0.54(0.53-0.55)$ & 81.4 \\
\hline \multicolumn{7}{|c|}{ The initial values } \\
\hline qSOFA & 5 & 35,462 & $3.29(2.51-4.29)$ & $0.33(0.22-0.47)$ & $0.90(0.82-0.94)$ & 79.1 \\
\hline SIRS & 5 & 35,462 & $1.93(1.20-3.15)$ & $0.78(0.68-0.86)$ & $0.37(0.25-0.51)$ & 92.1 \\
\hline \multicolumn{7}{|c|}{ The worst values } \\
\hline qSOFA & 3 & 17,387 & 6.89 (5.12-9.27) & $0.55(0.47-0.63)$ & $0.87(0.82-0.90)$ & 71 \\
\hline SIRS & 3 & 17,387 & $4.24(3.50-5.14)$ & $0.85(0.75-0.91)$ & $0.46(0.35-0.57)$ & 0 \\
\hline
\end{tabular}

qSOFA quick Sequential Organ Failure Assessment, SIRS systemic inflammatory response syndrome, $R R$ risk ratio, SEN sensitivity; SPE specificity; CI confidence interval

sensitivity and specificity of given cut-off points (e.g., qSOFA score $\geq 2$; SIRS $\geq 2$ ). Nevertheless, the AUC can represent the overall discriminatory ability. Regardless of whether comparisons were direct or indirect, they all consistently indicated that a qSOFA score $\geq 2$ was more specific but less sensitive in predicting mortality than a SIRS score $\geq 2$. Additionally, qSOFA had a superior positive likelihood ratio compared with that of SIRS, but SIRS had a relatively good negative likelihood ratio. Therefore, qSOFA criteria are no better or worse than SIRS criteria in identifying patients with a high risk of death in an ED setting. These risk stratification tools have different strengths and weaknesses. SIRS is a targeted, sensitive screening tool that is well suited for early care and prevention of missed cases. However, the focus of qSOFA is the specific identification of patients at an even higher risk of death, which could aid clinicians in deciding on subsequent care and treatment.

The choice of tool depends on the clinician's attitude towards resource use and health care, as well as infection-related mortality. In some ED settings, where infection mortality is relatively low and resources are limited, the lower sensitivity of the qSOFA is not a major drawback. Its high specificity and ease of use may help clinicians focus on patients who require more clinical attention. In ED settings that have a relatively high mortality rate of infections and are resource-rich, the most sensitive test (SIRS) may be preferred.

The following limitations of our review should be considered. (1) This meta-analysis revealed significant heterogeneity among the included studies. The studies' included patients had different infection types, and different outcome measures were used, such as in-hospital mortality or 30-day mortality. Studies used various designs, including prospective and retrospective observational studies, and they used different time points to calculate the scores. Despite these variations, comprehensive subanalyses showed conclusions similar to those of the main analysis. Considering studies that used different time points to calculate scores, different outcome measures, or different designs separately did not influence the conclusions. These analyses have significantly improved homogeneity without affecting the main conclusions. However, despite the multiple subanalyses conducted, the meta-analysis was still influenced by the inherent biases of the included studies and did not display any consistent source to explain the obvious heterogeneity. Some researchers have suggested that there is often a large degree of heterogeneity in meta-analyses of diagnostic studies [24]. We included all articles that 
directly evaluated qSOFA and SIRS using the same cohort patients to minimize heterogeneity when comparing qSOFA and SIRS. (2) A relatively small number of studies were included, which may not have enabled a complete assessment of the prognostic potential of qSOFA and SIRS.

\section{Conclusions}

In conclusion, our results suggested that both a qSOFA score $\geq 2$ and a SIRS score $\geq 2$ were strongly associated with mortality in ED patients with infections. However, it is also clear that qSOFA and SIRS have limitations as risk stratification tools for ED patients with infections. qSOFA appears to be a simple, rapid, and effective way to identify patients at high risk for death. However, it seems necessary to identify ways to improve its low sensitivity. Until then, it cannot completely replace the use of SIRS in the ED.

\section{Additional file}

Additional file 1 Hayden's criteria for quality assessment, modified to apply to studies of infection. (DOCX $18 \mathrm{~kb}$ )

\section{Abbreviations}

Cl: Confidence interval; DOR: Diagnostic odds ratio; ED: Emergency department; FN: False negatives; FP: False positives; ICU: Intensive care unit; NLR: Negative likelihood ratio; PLR: Positive likelihood ratio; qSOFA: Quick sequential organ failure assessment; RR: Risk ratio; SIRS: Systemic inflammatory response syndrome; SROC: Summary receiver operating characteristic curve; TN: True negatives; TP: True positives

\section{Acknowledgements}

This meta-analysis was conducted with the support of the Department of Respiratory Medicine, the Second Affiliated Hospital of Anhui Medical University. We sincerely thank everyone who provided assistance with our study.

\section{Author contributions}

Conceptualization: JJ JY JM. Data curation: JJ JY. Formal analysis: JJ JY. Funding acquisition: JY. Investigation: JJ JY JM. Methodology: JJ JY. Project administration: JY YL. Resources: JJ JY JM. Software: JJ. Supervision: JM YJ. Validation: JY. Visualization: JY YL. Writing - original draft: JJ. Writing review \& editing: JY YL. All authors read and approved the final manuscript.

\section{Funding}

This work was funded by the National Natural Science Foundation of China (grant number 8140010845).

\section{Availability of data and materials}

All data analysed or generated during this study are included in this article.

\section{Ethics approval and consent to participate}

Not applicable.

\section{Consent for publication}

Not applicable.

\section{Competing interests}

The authors declare that they have no competing interests.

\section{Publisher's Note}

Springer Nature remains neutral with regard to jurisdictional claims in published maps and institutional affiliations.
Received: 13 April 2018 Accepted: 4 July 2018

Published online: 11 July 2018

\section{References}

1. Vincent JL, Marshall JC, Namendyssilva SA, François B, Martinloeches I, Lipman J, Reinhart K, Antonelli M, Pickkers P, Njimi H. Assessment of the worldwide burden of critical illness: the intensive care over nations (ICON) audit. Lancet Respiratory Medicine. 2014;2(5):380-6.

2. Fleischmann C, Scherag A, Adhikari NK, Hartog CS, Tsaganos T, Schlattmann $P$, Angus DC, Reinhart K. Assessment of global incidence and mortality of hospital-treated Sepsis. Current estimates and limitations. Am J Respir Crit Care Med. 2016;193(3):259-72.

3. Peake SL, Delaney A, Bailey M, Bellomo R, Cameron PA, Cooper DJ, Higgins AM, Holdgate A, Howe BD, Webb SA. Goal-directed resuscitation for patients with early septic shock. N Engl J Med. 2014;371(16):1496-506.

4. Investigators TP. A randomized trial of protocol-based care for early septic shock. N Engl J Med. 2014;370(18):1683-93.

5. Priebe HJ. Early, goal-directed resuscitation for septic shock. N Engl J Med. 2015;373(6):1301-11.

6. Bone RC, Balk RA, Cerra FB, Dellinger RP, Fein AM, Knaus WA, Schein RMH, Sibbald WJ. Definitions for Sepsis and organ failure and guidelines for the use of innovative therapies in Sepsis. Chest. 1992;101(6):1644-55.

7. Levy MM, Fink MP, Marshall JC, Abraham E, Angus D, Cook D, Cohen J, Opal SM, Vincent J, Ramsay G. 2001 Sccm/esicm/accp/ats/sis international Sepsis definitions conference. Crit Care Med. 2003;31(4):1250.

8. Singer M, Deutschman CS, Seymour CW, Shankarhari M, Annane D, Bauer M, Bellomo R, Bernard GR, Chiche JD, Coopersmith CM. The third international consensus definitions for Sepsis and septic shock (Sepsis-3). Jama. 2016; 315(1):775-87.

9. Hayden JA, Côté $P$, Bombardier C. Evaluation of the quality of prognosis studies in systematic reviews. Ann Intern Med. 2006;144(6):427-37.

10. Higgins JPT. Measuring inconsistency in meta-analyses. Br Med J. 2003; 327(7414):557-60.

11. Whiting P, Rutjes AW, Reitsma JB, Bossuyt PM, Kleijnen J. The development of QUADAS: a tool for the quality assessment of studies of diagnostic accuracy included in. systematic reviews. 2003;3(3):25.

12. Reitsma JB, Glas AS, Rutjes AW, Scholten RJ, Bossuyt PM, Zwinderman AH. Bivariate analysis of sensitivity and specificity produces informative summary measures in diagnostic reviews. J Clin Epidemiol. 2005;58(10):982-90.

13. Moses LE, Shapiro D, Littenberg B: Combining independent studies of a diagnostic test into a summary roc curve: Data-analytic approaches and some additional considerations. Stat Med. 1993:12(14):1293-316.

14. Goulden R, Hoyle MC, Monis J, Railton D, Riley V, Martin P, Martina R, Nsutebu E: qSOFA, SIRS and NEWS for predicting inhospital mortality and ICU admission in emergency admissions treated as sepsis. Emerg Med J. 2018;35(6):345-9.

15. Ranzani OT, Prina E, Menéndez R, Ceccato A, Cilloniz C, Méndez R, Gabarrus A, Barbeta E, Li BG, Ferrer M: New Sepsis Definition (Sepsis-3) and Community-acquired Pneumonia Mortality: A Validation and Clinical Decision-making Study. Am J Respir Crit Care Med. 2017;196(10):1287-97.

16. González DCJ, Julianjiménez A, Gonzálezmartínez F, J Á, Piñera P, Navarrobustos C, Martinezortiz dZM, Llopisroca F, Debán FM, Gamazodel RJ. prognostic accuracy of SIRS criteria, qSOFA score and GYM score for 30-daymortality in older non-severely dependent infected patients attended in the emergency department. Eur J Clin Microbiol Infect Dis. 2017;36(12):1-9.

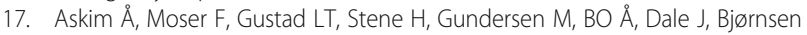
LP, Damås JK, Solligård E. Poor performance of quick-SOFA (qSOFA) score in predicting severe sepsis and mortality - a prospective study of patients admitted with infection to the emergency department. Scand J Trauma Resusc Emerg Med. 2017;25(1):56.

18. Moskowitz A, Patel PV, Grossestreuer AV, Chase M, Shapiro NI, Berg K, Cocchi MN, Holmberg MJ, Donnino MW, Science CFR. Quick sequential organ failure assessment and systemic inflammatory response syndrome criteria as predictors of critical care intervention among patients with suspected infection. Crit Care Med. 2017;45(11):1813.

19. Williams JM, Greenslade JH, Mckenzie JV, Chu K, Brown AF, Lipman J. Systemic inflammatory response syndrome, quick sequential organ function assessment, and organ dysfunction: insights from a prospective database of ED patients with infection. Chest. 2017;151(3):586.

20. Freund $Y$, Lemachatti $N$, Krastinova E, Van LM, Claessens YE, Avondo A Occelli C, Feral-Pierssens AL, Truchot J, Ortega M. Prognostic accuracy of 
Sepsis-3 criteria for in-hospital mortality among patients with suspected infection presenting to the emergency department. Jama. 2017;317(3):301

21. Henning DJ, Puskarich MA, Self WH, Howell MD, Donnino MW, Yealy DM, Jones AE, Shapiro NI. An emergency department validation of the SEP-3 Sepsis and septic shock definitions and comparison with 1992 consensus definitions. Ann Emerg Med. 2017;70(4):544.

22. Ho KM, Lan NS. Combining quick sequential organ failure assessment with plasma lactate concentration is comparable to standard sequential organ failure assessment score in predicting mortality of patients with and without suspected infection. J Crit Care. 2016;38:1.

23. Andaluz-Ojeda D, Nguyen HB, Meunier-Beillard N, Cicuéndez R, Quenot JP, Calvo D, Dargent A, Zarca E, Andrés C, Nogales L. Superior accuracy of midregional proadrenomedullin for mortality prediction in sepsis with varying levels of illness severity. Ann Intensive Care. 2017;7(1):15.

24. Dinnes J, Deeks J, Kirby J, Roderick P. A methodological review of how heterogeneity has been examined in systematic reviews of diagnostic test accuracy. Health Technol Assess. 2005;9(12):1-113.

Ready to submit your research? Choose BMC and benefit from:

- fast, convenient online submission

- thorough peer review by experienced researchers in your field

- rapid publication on acceptance

- support for research data, including large and complex data types

- gold Open Access which fosters wider collaboration and increased citations

- maximum visibility for your research: over $100 \mathrm{M}$ website views per year

At BMC, research is always in progress.

Learn more biomedcentral.com/submissions 